\title{
Valuing provisioning ecosystem services in agriculture: The impact of climate change on food production in the United Kingdom
}

\author{
Carlo Fezzi ${ }^{1}$, Ian Bateman, Tom Askew, \\ Paul Munday, Unai Pascual, Antara Sen, Amii Darnell
}

\begin{abstract}
This paper provides an estimate of the contribution of the ecosystem to the provisioning services generated by agriculture. This is achieved by estimating the changes in productivity generated by a marginal alteration in ecosystem inputs. As an example, we consider the changes in rainfall and temperature projected by the recent UK Climate Impacts Programme (UKCIP). The analysis implements a spatially explicit, econometric model of agricultural land use based on the methodology recently developed by Fezzi and Bateman (2011). Land use area and livestock stocking rates are then employed to calculate farm gross margin estimates of the value of changes in provisioning ecosystem services. Findings suggest that the variation in ecosystem inputs induced by climate change will have substantial influence on agricultural productivity. Interestingly, within the UK context climate change generates mainly positive effects, although losses are forecasted for those southern areas most vulnerable to heat-stress and drought.
\end{abstract}

\footnotetext{
${ }^{1}$ Corresponding author contact: CSERGE, School of Environmental Sciences, University of East Anglia, Norwich, NR4 7TJ, UK. Email: c.fezzi@uea.ac.uk. This research was supported by the Social and Environmental Economic Research (SEER) into Multi-Objective Land Use Decision Making project; funded by the UK Economic and Social Research Council, reference RES-060-25-0063.
} 


\section{Introduction}

The Millennium Ecosystem Assessment (2005) classifies agricultural food production as a 'provisioning service' dependent in major part on the inputs provided by natural systems. However, such production is also crucially determined by inputs of other forms of capital including farmer expertise, machinery and other manufactured inputs. Therefore, estimates of the value of ecosystem service inputs to the food production process need to control for these other human and manufactured capital inputs (Bateman et al., 2011). With such controls in place, variations in ecosystem service inputs can provide unbiased, 'clean' estimates of their contribution to the value of food production. As a topical illustration of this approach, in this paper we estimate the value of climate related ecosystem services to agricultural production by analysing certain of the central scenarios provided by the United Kingdom Climate Impacts Programme (UKCIP, 2009). These scenarios preoject variations in rainfall and temperature arising from future climate change. Our analysis examines the implications of such variation for agricultural production and incomes in the United Kingdom (UK).

Numerous studies indicate that global warming will have major impacts on agriculture, especially in the lower latitudes (Intergovernmental Panel on Climate Change, IPCC, 2007). Potential threats for agricultural production include: (a) prolonged and more frequent droughts, (b) changes in rainfall distribution, (c) increase in storms and other extreme weather events, (d) rising sea levels, (e) increased and changing pest loads, (f) increased risk of heat stress in livestock farming, and (g) possible changes in soil water balance. In addition to these, farmers will need to adapt to climate change mitigation policies, likely to involve increased costs of carbon emissions reflected in both their inputs (e.g. fertilisers) and outputs (e.g. higher transport costs).

Despite these serious concerns, climate change seems likely to also generate new opportunities for agriculture which, if given the appropriate policy environment, may not only reduce deprivation but reverse the fortunes of a sector in long-term economic decline. For example, increased $\mathrm{CO}_{2}$ concentrations in the atmosphere may increase the rate of photosynthesis, reduce the amount of water required per unit of biomass and lead to higher crop yields (UK Department for Environment, Food and Rural Affairs, Defra, 2000). Similarly increased temperatures may accelerate crop growth, shorten the growing season and expand climatic suitability for agriculture into uplands and higher latitudes.

Different approaches have been proposed to measure the impact of climate change on agriculture. Schlenker et al. (2006) divides them into three broad categories: (a) agronomic models, (b) Computable 
General Equilibrium (CGE) models and (c) Ricardian analysis. Agronomic models use crop growth simulators (e.g. Adams, 1989) or historical crop yield data (e.g. Lobell et al., 2011) to predict the impact of temperature and precipitation changes on agricultural output. A drawback of this approach is that it does not easily incorporate all those measures that farmers can undertake to adapt to climate change (e.g. switching activities, change husbandry practices, etc.). Furthermore, these analyses typically focus on the agricultural sector, and ignore the linkages with the rest of the economy.

Wider linkages are explicitly addressed by CGE models, in which agriculture is modelled as one of the sectors within the whole economy (e.g. Nordhaus and Yang, 1996). They typically encompass the relationships between all major economic sectors, international trade and technological change. The advantages of CGE models are that they allow prices to be endogenous and resources to move freely among sectors and countries. However, this generality comes at the cost of substantial aggregation, in which heterogeneous sectors are portrayed as representative farms and firms. This can lead to the loss of that crucial spatial variation in the physical environment which substantially determines agricultural production (e.g. Wu et al., 2004) and is vital to the determination of ecosystem service inputs and their value.

A third strategy, which has gained considerable attention in recent years, is the Ricardian approach, introduced by Mendelsohn et al. (1994). This is essentially a hedonic regression analysis of farmland values, based on the notion that, in competitive markets, the price of farmland will reflect expected discounted profits. The advantages of this approach are that it is highly spatially explicit and that it automatically captures adaptation, since farmers are adjusting inputs and practices to match local conditions. A drawback of Ricardian analyses is that they do not explicitly model land use choices and, therefore, while accounting for adaptation, do not provide information on how farmers adapt.

In this paper we address this issue by directly modelling agricultural land use decisions via a spatially explicit, structural econometric model based on the methodology recently introduced by Fezzi and Bateman (2011). This approach analyses land use decisions within a theoretically consistent, econometric structure embracing crop and livestock production, input applications and profits. This framework predicts how farmers respond to changes in agricultural policy, costs, prices and the wider natural environment, including climate related variables. The model is validated through out-of-sample comparisons of actual and predicted values. In addition, we contrast the performance of our structural approach with the traditional, reduced-form land share model, widely applied in the literature to analyze land use (e.g. Wu and Segerson, 1995; Langpap et al., 2008; for a review see Brady and Irwin, 2011). 
The econometric framework adopted in this paper is highly appropriate for capturing the spatial heterogeneity which characterises land use decisions, their values and consequent environmental impacts. A key advantage of this approach is that land use predictions can be linked to their implications for other ecosystem services which are determined by the agriculture, such as farmland biodiversity, recreation and carbon storage as discussed in the accompanying papers of this special issue (Abson et al., 2012; Bateman et al., 2012; Sen et al., 2012). An issue arising from the spatially sensitive agricultural census data used as the basis of the present analysis is the absence of direct information on the incomes of farms in the highly detailed, $2 \mathrm{~km}$ grid squares used as the basis of data collection. In ongoing work (Fezzi et al., 2011) we use additional datasets to examine the theoretically preferred profit measure (Just, 2000). However, in the present paper we use the Farm Gross Margin (FGM) measure commonly applied in agricultural economic studies (e.g. Fezzi et al. 2008; National Statistics, 2010), this being simply the difference between farm revenues and their associated variable costs.

The model is developed using data covering all of England, Scotland and Wales. The resulting model is then transferred to Northern Ireland (for which data was not available) to provide a UK wide analysis. Results suggest that, ceteris paribus (and in particular assuming no offsetting policy or unforeseen technology response), climate change is likely to have a negative impact on FGM in the southern lowlands of England where droughtiness problems may arise, particularly within the dairy sector. However in Northern England, Scotland and Wales FGM values will generally increase as warmer, dryer conditions within the growing season boost the potential for shifts out of low intensity pastoral activities towards higher return options including, in some areas, arable outputs.

The rest of this paper is organised as follows. Section 2 presents the econometric framework, the estimation results and the predictive performance of the model. Section 3 illustrated the climate change scenarios and the estimated impacts on agriculture. Section 4 concludes illustrating also the main caveats of our analysis.

\section{The econometric land use model}

This section presents a brief overview of the model specification, illustrates the data used for estimation and summarises the main results. For a more detailed discussion of the methodology see Fezzi and Bateman (2011). 


\section{Theoretical model}

We assume that each farmer maximizes profits per unit of land by solving the following constrained optimization problem:

(1) $\pi^{L}(\mathbf{p}, \mathbf{w}, \mathbf{z}, L)=\max _{s_{1}, \ldots, s_{h}}\left\{\pi\left(\mathbf{p}, \mathbf{w}, \mathbf{z}, L, s_{1}, \ldots, s_{h}\right): \sum_{i=1}^{h} s_{h}=1\right\} \cdot$

where $\pi^{L}$ (.) are profits per unit of land, $\mathbf{y}$ is the vector of $m$ outputs, with $\mathbf{r}$ the vector of $n$ inputs, $\mathbf{p}$ the vector of strictly positive output prices, $\mathbf{w}$ the vector of strictly positive input prices, $\mathbf{s}$ the vector of $h$ land share allocations, $L$ the total land available and $\mathbf{z}$ the vector of $k$ other fixed factors (which may include physical and environmental characteristics, policy incentives and constraints, etc.). This profit function is positively linearly homogenous and strictly convex in input and output prices. By using Hotelling's Lemma we can derive the output supply $\left(\mathbf{y}^{\mathbf{L}}\right)$ and input demand $\left(\mathbf{r}^{\mathbf{L}}\right)$ equations per unit of land (hereafter we will refer to these quantities as input and output intensities) as:

(2.a) $y_{i}{ }^{L}(\mathbf{p}, \mathbf{w}, \mathbf{z}, L)=\frac{\partial \pi^{L}(\mathbf{p}, \mathbf{w}, \mathbf{z}, L)}{\partial p_{i}}=\frac{\pi^{L}\left(\mathbf{p}, \mathbf{w}, \mathbf{z}, L, \bar{s}_{1}, \ldots, \bar{s}_{h}\right)}{\partial p_{i}}$, with $i=1, \ldots, m$, and

(2.b) $r_{j}^{L}(\mathbf{p}, \mathbf{w}, \mathbf{z}, L)=\frac{\partial \pi^{L}(\mathbf{p}, \mathbf{w}, \mathbf{z}, L)}{\partial w_{j}}=\frac{\pi^{L}\left(\mathbf{p}, \mathbf{w}, \mathbf{z}, L, \bar{s}_{1}, \ldots, \bar{s}_{h}\right)}{\partial w_{j}}$, with $j=1, \ldots, n$,

and the superscript on $s$ indicates the optimal shares, i.e. the shares that satisfy (1). The optimal land use shares are defined by fixed order conditions of (1):

(3) $\frac{\partial \pi^{L}\left(\mathbf{p}, \mathbf{w}, \mathbf{z}, L, \bar{s}_{1}, \ldots, \bar{s}_{h}\right)}{\partial s_{i}}=\lambda \quad$ for $i=1, \ldots, h$.

The Lagrange multiplier $\lambda$ corresponds to the land shadow price, or marginal rent, and is assumed to be equal across all land uses. When corner solution exists (i.e. not all crops are cultivated on all farms) this equation still holds for all crops receiving non-zero allocation (Chambers and Just, 1989). When these 
equations are linear in the optimal land allocations, then including the constraint that the sum of the shares needs to be equal to one leads to a linear system of $h$ equations in $h$ unknowns which can be solved to obtain the optimal land allocation as a function of $\mathbf{p}, \mathbf{w}, \mathbf{z}$ and $L$ (Fezzi and Bateman, 2010).

For estimation, we specify the empirical profit function per unit of land as a Normalized Quadratic (NQ). We indicate with $w_{n}$ the numeraire good, with $\mathbf{x}=\left(\mathbf{p} / w_{n}, \mathbf{w} / w_{n}\right)$ the vector of normalized input and output (netput) prices, with and with $\bar{\pi}^{L}=\pi^{L} / w_{n}$ the normalized profit per unit of land, with $\mathbf{z}^{*}=(\mathbf{z}, L)$ the vector of fixed factors including policy and environmental drivers and the total land available $L$. The NQ profit function is defined as:

$$
\text { (4) } \begin{aligned}
\bar{\pi}^{L}= & \alpha_{0}+\sum_{i=1}^{m+n-1} \alpha_{i} x_{i}+\frac{1}{2} \sum_{i=1}^{m+n-1} \sum_{j=1}^{m+n-1} \alpha_{i j} x_{i} x_{j}+\sum_{i=1}^{h-1} \beta_{i} s_{i}+\frac{1}{2} \sum_{i=1}^{h-1} \sum_{j=1}^{h-1} \beta_{i j} s_{i} s_{j}+\sum_{i=1}^{k+1} \gamma_{i} z_{i}^{*}+ \\
& +\frac{1}{2} \sum_{i=1}^{k+1} \sum_{j=1}^{k+1} \gamma_{i j} z_{i}^{*} z_{j}^{*}+\sum_{i=1}^{m+n-1} \sum_{j=1}^{h-1} \delta_{i j} x_{i} s_{j}+\sum_{i=1}^{m+n-1} \sum_{j=1}^{k+1} \phi_{i j} x_{i} z_{j}^{*}+\sum_{i=1}^{h-1} \sum_{j=1}^{k+1} \varphi_{i j} s_{i} z_{j}^{*},
\end{aligned}
$$

This representation includes only $h$ - 1 land use shares, since one of these can be obtained via the additivity constraint and is therefore redundant. Symmetry is imposed by assuming $\alpha_{i j}=\alpha_{j i}, \beta_{i j}=\beta_{j i}$ and $\gamma_{i j}=\gamma_{j i}$, whereas linear homogeneity is ensured by construction. Input and output intensities can be derived via Hotelling's Lemma, as shown in (2.a) and (2.b). For instance, if $x_{i}$ indicates the normalized price of cereals, the equation corresponding to cereal yield $\left(y_{i}^{L}\right)$ can be derived as:

(5) $\frac{\partial \bar{\pi}^{L}}{\partial x_{i}}=y_{i}^{L}=\alpha_{i}+\sum_{j=1}^{m+n-1} \alpha_{i j} x_{j}+\sum_{j=1}^{h-1} \delta_{i j} s_{j}+\sum_{j=1}^{k+1} \phi_{i j} z_{j}^{*}$,

Solving the system of fixed order conditions (3) by introducing the land additivity constraint $\left(\sum_{j=1}^{h} s_{j}=1\right)$ leads to the following, reduced-form linear equations describing land use allocations:

(6) $s_{i}=\theta_{i}+\sum_{j=1}^{m+n-1} \theta_{j i} x_{j}+\sum_{j=1}^{k+1} \eta_{j i} z_{j}^{*}$, for $i=1, \ldots, h-1$,

with $\theta$ and $\eta$ being the vectors of the parameters to be estimated, which are non-linear combinations of the structural parameters in the NQ profit function (4). 


\section{Estimation}

As noted previously, micro-data on land use are often characterised by corner solutions (not all farms cultivate all possible crops). Therefore imposing normal disturbances and implementing Maximum Likelihood (ML) estimation techniques will yield inconsistent estimates of the land use share and input and output intensity equations (Amemiya, 1973). We address this issue by specifying a Tobit system of equations (Tobin, 1958), in which the latent shares $s_{i}^{*}$ are defined as in (6) plus additive normal residuals. Observed shares are specified as: $s_{i}=0$ if $s_{i}^{*} \leq 0, s_{i}=1$ if $s_{i}^{*} \geq 1$ and $s_{i}=s_{i}^{*}$ otherwise. This transformation can be interpreted by recalling that the fixed order conditions of the profit maximization problem are equal to the land shadow prices. For this reason, censoring from below (above) implies that the corresponding land use shadow price is lower (higher) than those of alternative uses. One concern arising from this specification is that the adding-up restriction (i.e. the sum of all land use shares needs to be equal to one) is not satisfied for the observed shares. Following Pudney (1989), we address this issue by treating one of the shares as a residual category and estimating the remaining $h-1$ equations as a joint system.

When the number of equations is higher than three the ML estimation of a Tobit system requires the evaluation of multiple Gaussian integrals which is computationally extremely intensive. To address this issue, we follow the approach suggested by Yen et al. (2003), who propose to approximate the multivariate Tobit with a sequence of bivariate models, deriving a consistent Quasi Maximum Likelihood (QML) estimator. More precisely, we implement the algorithm proposed by Fezzi and Bateman (2011), which extends the Yen et al. (2003) approach to the two-limit Tobit model by including censoring from above and by allowing the standard errors to vary across observations as a function of a vector of exogenous variables. This QML estimator is consistent, allows the estimation of cross-equation correlations and the imposition of cross-equation restrictions. We implement the same QML approach to estimate the system of netput equations (5), but clearly neither discarding one of the equations nor applying any censoring from above.

\section{Data sources}

In order to correctly assess the market, policy and environmental drivers of land use change, this analysis employs a unique database, which integrates multiple sources of information dating back to the late 1960s. The resulting data, collected on a $2 \mathrm{~km}$ grid square (400ha) basis, cover the entirety of England, Scotland and Wales (Great Britain; GB) and encompass, for the past 40 years: (a) land use shares and livestock numbers, (b) environmental and climatic determinants, (c) policy and other drivers. As noted previously, 
yield and profit data are not available at the detailed spatial resolution required by this analysis and so we employ the FGM measure of farm output value.

Agricultural data, including the number of hectares of each farm land use and numbers of head for various livestock, were extracted from the June Agricultural Census (JAC), obtained from the on-line EDINA (www.edina.ac.uk) data source. These are in turn derived from information provided by the Department of Environment, Food and Rural Affairs (DEFRA), the Scottish Government, and Welsh Assembly. This data cover the entirety of GB for seventeen, unevenly spaced, years between 1969 and 2006. This yields roughly 60,000 grid-square records each year, amounting to over 1 million sets of grid-square records for the overall analysis. Each set includes separate livestock records for dairy cows, beef cows and sheep. Land use areas are also specified for cereals (including wheat, barley, oats, etc.), oilseed rape, root crops (potatoes and sugar beet), temporary grassland (grass being sown every 3 to 5 years and typically part of an arable crop rotation), permanent grassland (grassland maintained perpetually without reseeding) and rough grazing. These land use types together account for more than $88 \%$ of the total agricultural land within the country and represent the $h-1$ explicitly modelled land uses in equation (6). We include the remaining $12 \%$ in an "other" land category encompassing horticulture, other arable crops, woodland on the farm, set-aside, bare, fallow and all other land (ponds, paths, etc.). Descriptive statistics for the agricultural land use types and livestock numbers are reported in Table 1 for three illustrative years and for the total dataset. ${ }^{2}$ [add a note here on the conversion]

Potential environmental drivers of agricultural land decisions use were also obtained for our complete $2 \mathrm{~km}$ grid square coverage of GB. Climate related variables for the growing season (April-September) include average temperature and accumulated rainfall. These were initially obtained as $5 \mathrm{~km}$ grid square values, calculated using the same baseline as that employed by the UK Climate Impacts Programme in their most recent assessment (UKCIP09, available at www.ukcip.org.uk $)^{3}$ which we then interpolate to our $2 \mathrm{~km}$ square grid. Other environmental and topographic variables which may influence farmers' decisions include soil depth to rock $(d r)$, volume of stones (stone) and 5 dummy variables representing soil texture

\footnotetext{
${ }^{2}$ As described on the EDINA website, grid-square land use estimates can sometimes overestimate or underestimate the amount of agricultural land within an area, since their collection is based on the location of the main farm house. For example, when a farm's agricultural land belongs to more than one parish, all the land use is assigned to that parish in which the main farm is registered. For this reason the recorded areas of land use and the numbers of livestock can sometimes significantly overestimate the real values. For instance, it is not uncommon for the recorded value of rough grazing to exceed the total amount of land within a grid square (400 ha). We correct this feature by rescaling the sum of the different agricultural land use areas assigned to each grid square to match with the total agricultural land derived from the Agricultural Land Classification (ALC) system published by DEFRA and the Welsh Assembly (data available at: http://www.naturalengland.org.uk/). However, we did not apply any correction factor to the livestock numbers.

${ }^{3}$ The UKCIP baseline uses monthly data available from the Met Office website (www.metoffice.gov.uk) to calculate averages for the period 1961-1990.
} 
(fine, medium fine, medium, coarse, peaty). Those soil characteristics are derived from the $1 \mathrm{~km}$ raster library of the European Soil Database (Van Liedekerke et al., 2006), which we aggregate to a $2 \mathrm{~km}$ square level. Finally, we include mean altitude (alt) and the grid square share of agricultural land with slopes higher than 6 degrees (smore6), both derived via GIS analysis of the Ordnance Survey Digital Terrain Model (http://www.ordnancesurvey.co.uk).

\section{[ Table 1 about here ]}

\section{Table 1: Descriptive statistics}

Regarding the policy determinants, we include the share of each grid square designated as National Park, Nitrate Sensitive Area (NSA) and Environmentally Sensitive Area (ESA). ESAs, introduced in 1987 and extended in subsequent years, were launched to conserve and enhance areas of particular landscape and wildlife significance. Participation in ESA schemes is voluntary and farmers receive monetary compensation for engaging in environmentally friendly farming practices, such as converting arable land to permanent grassland, establishing hedgerows, etc. NSAs were introduced in 1990 with the intention of reducing nitrate levels in selected aquifers and ground-waters used for public water supply. As per ESAs, NSA participation is voluntary and the scheme has been extended since its initial introduction. Farms located within the boundaries of National Parks can benefit from direct payments if they manage their land for environmental enhancement and undertake various low-intensity activities.

Finally, a lack of information on the spatial variation of market input and output prices and technology dictates that we do not model these explicitly but rather control for them as fixed effects via yearly dummies. This choice allows us to parsimoniously control for all time-varying omitted factors and isolate the effect of climate and other environmental variables on land use decisions.

\section{Results}

We implement the QML approach to estimate two censored Tobit systems: a 3 livestock intensity (dairy cows, beef cows, sheep) equation system and a 6 land use share (cereal, oilseed rape, root crops, temporary grassland, permanent grassland, rough grazing) system. To control for spatial autocorrelation we estimate the model using only a fraction of our data, selected via spatial sampling (e.g. Carrión-Flores and Irwin, 2004; Fezzi and Bateman, 2011). This is defined by randomly extracting one grid square and then sampling every fourth grid cell along both latitude and longitude axes (i.e., considering only the corners in a four by four square of cells), leaving a subsample of roughly 51,000 observation. We use a full quadratic 
specification of all the environmental determinants (i.e. second order polynomials with interactions) to capture possible non-linear relations. The land use systems showed convergence problems and we therefore estimate each equation separately, as a heteroskedastic Tobit. Furthermore, since omitted, cell-specific factors can be present, we correct the variance-covariance matrix allowing the residuals to be correlated among observations pertaining to the same cell in different years (Williams, 2000).

For illustrative purposes, Table 2 reports the most important parameters of two of the equations in the system, that for oilseed rape and temporary grassland. The sign and magnitude of the coefficients are consistent with prior expectations. Considering the environmental determinants of land use, favourable conditions for crop growth (lower volume of stones, deeper soils, flatter land, etc.) increase the share of arable land. However, effects are non-linear. For example, focusing on the influence of climate, the coefficients on rainfall and temperature describe U-shaped relationships in both land use share equations. Considering the policy variables, ESA, NSA and National Parks decrease the share of oilseed rape within a grid square. National Parks also reduces the amount of temporary grassland, which is substitute by rough grazing and other low intensity pasture. Finally, also the parameters of the variance equations (not reported in the Table to preserve space) are highly significant, correcting for heteroskedastic errors.

\section{[ Table 2 about here ]}

Table 2: Selected land use share equations estimates

\section{Predictive ability}

We evaluate the fit and predictive ability of our structural model by comparing its out-of-sample forecasting performance against that of an established benchmark: the logit land use share model introduced by Lichtenberg (1989), Wu and Segerson (1995) and Plantinga (1996) and applied extensively thereafter. ${ }^{4}$ Table 3 reports the Mean Absolute Error (MAE) statistics for the land use share and livestock number equations calculated as the mean absolute value of the difference between the predictions and the actual JAC data. ${ }^{5}$ Our approach captures a significant proportion of the variability of the endogenous variables. For example, the MAE for cereals is approximately one-third of the standard deviation.

\footnotetext{
${ }^{4}$ The multinomial logit model is specified including the same explanatory variables of the structural model and estimated with Ordinary Least Squares (OLS) as a system of log odds of shares, following Zellner and Lee (1965). Since this model is undefined when there are zero values in the dependent variables, in each observation we set to a very small value (0.1 ha) all uses with no allocated land, as proposed by Wu and Segerson (1995).

${ }^{5}$ Note that, due to the availability of data for the most recent period, this comparison is conducted for the whole of England and Wales in 2004 rather than for all of Great Britain. Since only 5\% of the 2004 data are used to estimate the model, this consists of mainly out-of-sample forecasting. Therefore it is an appropriate yardstick to compare models performances avoiding the risk of preferring an over-fitting specification.
} 
Importantly, despite the constraints included in our model by its structural underpinnings, our approach still yields results which are superior to the logit for almost all land use categories (root crops being a very marginal exception). For this reason, we can conclude that in this application the structural model generally outperforms the commonly used benchmark. This is particular significant given the inability of the logit approach to model livestock numbers, despite these being one of the most significant sources of both agricultural values and externalities.

\section{[ Table 3 about here ]}

Table 3: Forecasting performance

A standard validity analysis might end with the classic test results reported in Table 3 . However, a sterner test of the predictive ability of our model, demonstrating its ability to forecast the spatial pattern of land use is given in Figure 1. This maps actual and predicted shares of both cereals and rough grazing for 2004. Visual inspection of such maps provides a much more stringent examination of where a model performs most and least effectively. While there are some minor differences (e.g. for the cereals maps there is evidence of minor over-prediction in the Midlands and under-prediction in Eastern Scotland), the overall pattern is one of very strong spatial predictive performance. One other observation is that the maps of 'actual' values are somewhat more blocky than predictions. This is obvious not a shortcoming of the model, but is a drawback of the raw JAC data being aggregated to somewhat larger grids in some years. ${ }^{6}$

[ Figure 1 about here ]

Figure 1: Cereals and rough grazing in 2004: model predictions (LHS) and JAC data (RHS)

\section{Climate change scenarios}

The econometric model estimated in the previous section covers all of GB and yet is based on and predicts for a fine-scale spatial resolution. It encompasses the variation in environmental conditions and farmer behaviour characterising the heterogeneous nature of British agriculture. This section considers impacts on agricultural land use and livestock numbers as well as consequences for FGM of the projected changes in temperature and precipitation provided by the UKCIP (2009).

\footnotetext{
${ }^{6}$ For detailed discussion see http://edina.ac.uk/agcensus/description.html (accessed 14 September 2011).
} 
UKCIP provides the most up-to-date and spatially explicit ( $25 \mathrm{~km}$ grid square resolution) projections of change in the UK climate. In this analysis we incorporate within our model the UKCIP (2009) projections of monthly average temperature and precipitation during the crop growing season (from April to September) from our 2004 baseline up to 2060. Descriptive statistics for various points within this period are presented in Table 4.

[Table 4 about here ]

Table 4: Descriptive statistics of the climatic variables (baseline and scenarios)

The UKCIP data summarised in Table 4 correspond to the low and high emission (respectively the SRES B1 and SRES A1FI) scenarios in the IPCC Special Report on Emissions Scenarios (Nakicenovic and Swart, 2000). Mean growing season temperatures increase from $14.9^{\circ} \mathrm{C}$ in our baseline year of 2004 to just above $18^{\circ} \mathrm{C}$ in 2060 . In contrast growing season precipitation declines over the same period such that the overall picture is one of warmer, drier growing seasons. Figure 2 illustrates the spatial pattern of these changes. Careful consideration shows that increases in temperature are fairly even across the country while decreases in precipitation are somewhat larger in the south eastern lowlands of England.

[ Figure 2 about here ]

Figure 2: Mean temperature (left hand pair) and precipitation (right hand pair) in the growing season in 2004 and 2040 under the UKCIP high emissions scenario.

By applying the econometric model developed in Section 2 to the UKCIP scenarios we derive the impacts of climate change on UK agricultural land use. Since farming activities, present and future environmental and climatic conditions in Northern Ireland (NI) fall within the range of observations for GB we feel confident in applying parameters from our estimated model to the former area. However, as illustrated in Figure 2, some parts of the south eastern lowlands of England are expected to endure climate change conditions which falls outside the range of previous observations used to estimate the model. For this reason, conclusions have to be interpreted cautiously for such areas. Furthermore, in order to provide a clean estimate of the impacts of climate change we hold technological responses (e.g. the introduction of new crop types), prices and policy constant at the baseline. Therefore, these scenarios are not projections of the future, but rather illustrate, ceteris paribus, the impact of climate change on the current agricultural sector and can be used to justify changes in those various fixed factors (e.g. policy responses).

\section{Results: The impact of climate change on UK agriculture}


Table 5 provides descriptive statistics regarding the expected impacts of climate change on UK agriculture in terms of effects on land use and livestock intensities. While some pathways of change are monotonic across time, others are not. The scenarios entail an overall increase in permanent and temporary grassland and a reduction in rough grazing grassland. This is reflected in the livestock which these various grazing types support; with dairying increasing while both and beef and sheep numbers fall. The net increase in land for high quality livestock is in considerable part met by a reduction in cereal areas which is further exacerbated by an increase in the 'other farmland' category, including crops that are currently marginal but would become increasing viable under a dryer and warmer climate. Oilseed rape and roots remain relatively small with the former decreasing and the latter increasing, although both changes are minor in absolute terms.

[ Table 5 about here ]

Table 5: Average projected land uses hectares and livestock numbers

Figure 3 presents maps of changes for selected land use and livestock types, those being cereals, temporary grassland and dairy cattle. Cereals are projected to significantly decrease in the South and East if England as the warmer climate increases opportunities for new crops. However, this is somewhat offset by an increase in cereals in eastern Scotland as the same processes reduce problems of cold and waterlogging in that area, increasing the amount of land suitable for arable cultivations. Another interesting trend is provided by the second row, illustrating the projections for temporary grassland. We observed a marked East-West divide, with this land use type increasing in the West, mainly driven by the warmer climate, and decreases in the East, most likely because of draughtiness problems. Finally, the number of dairy cows is, ceteris paribus, expected to increase significantly, driven both by the changes in land use but also by the more favourable climatic conditions.

[ Figure 3 about here ]

Figure 3: Change in land use (cereals and temporary grassland) and livestock numbers (dairy cattle) under the UKCIP low emission scenario for 2020, 2040, 2060 
By coupling the projected patterns of land use and livestock numbers with average FGM values per cropped hectare and livestock head, we can derive estimates of the financial impact of climate change on UK agriculture. Figure 3 illustrates changes from the baseline (2004) FGM across the UK evaluated at three points in time (2020, 2040 and 2060). On each occasion we use the prices prevailing in the baseline year and ignore intervening inflation and other possible factors influencing prices to yield a real value comparison ${ }^{7}$. The maps show a clear North-South and East-West divide. In Northern Ireland, Scotland, Wales and the uplands of Northern England climate change is expected to boost FGM values. This conforms well to common sense expectations. These areas are characterised by relatively low temperatures retarding plant growth and high rainfall leaving areas prone to waterlogging. The increased temperatures and lower rainfalls projected under the UKCIP scenarios should, therefore, ameliorate both of these problems. In contrast the lowland areas of southern and eastern England are relatively closer to droughtiness problems which climate change should exacerbate.

\section{[ Figure 5 about here ]}

Figure 4: Impact of climate change (UKCIP low emission scenario, 2020, 2040, 2060) on farm gross margin (£/ha) in 2020 compared to its level in 2004.

\section{Conclusions and caveats}

This analysis applies a recently developed, spatially explicit agricultural land use model to estimate changes in land use, livestock numbers and agricultural incomes arising as a result of climate change in the UK. Official climate change scenarios are taken from the most recent UKCIP projections and findings suggest that these imply substantial modifications in both land use and income within the farming sector. Interestingly, climate change impacts appear to be highly spatially variable, generating both positive and negative impacts in different areas of the UK. These spatial patterns include a new North-South divide, reversing the contemporary direction of inequality, with the winners being in the currently poorer Northern and upland areas and the losers being in the richer South-East lowlands.

While these are, we believe, useful contributions to both understanding and policy formation, several caveats need to be taken into account when considering the results produced by this analysis. First, the

\footnotetext{
${ }^{7}$ FGM forecasts for 2004 taken from Fezzi et al. (2010) as follows: "cereals" $=£ 290 /$ ha, "root crops" $=£ 2425 /$ ha, "oilseed rape" $=£ 310 /$ ha, "dairy" = $£ 576 /$ head, "beef" = $£ 69 /$ head, "sheep" = $£ 9.3 /$ head, "other land" assumed to have the same FGM/ha of cereals. Appendix 1 provides an analysis of the impacts of variation in these prices.
} 
model scenarios are not predictions of the future, but rather represent the impact of climate change ceteris paribus, i.e. keeping all other drivers of land use and agricultural production fixed to their baseline levels (year 2004). Therefore, for example, market prices and government involvement (subsidies, levies, milk quota, etc.) are assumed to stay constant. Any other assumption would undermine the clarity of these results.

Aside from environmental and policy drivers, changes in prices and technology also have massive impacts on land use and needs to be included within any robust model of farm decision making. Between 1920 and 1980, for example, wheat yield in the UK more than tripled with technological improvement being one of the main drivers underpinning this significant growth (Austin and Harnold, 1989). Similarly the impact of changes in price can massively influence land use. For example, substantial price rises, driven in considerable part by CAP arable area payments, has resulted in a more than 50 fold increase in GB oilseed rape area since the 1970s. Omission of such crucial drivers would obviously bias our land use model. For this reason, while we do not explicitly model prices and technology in our analytic framework, we control for their influence via yearly fixed effects. Moreover, the pervasive nature of the impact of technological and price change also means that the impacts of climate change can be either mitigated or enhanced by shifts in technology and/or prices. Decision makers need to take all factors into account when considering the formation of future policy. However, the present paper seeks to provide a clean and unbiased estimate of the impacts of expected climate change on UK agriculture. For this reason, in the present analysis we deliberately hold prices and technology constant at baseline levels. This allows us to observe the pure, unalloyed effects of climate change.

A further aspect of the approach to potential technical change is that we deliberately do not consider the introduction of possible new crops. This includes diversions into crops types (such as vineyards) used in warmer, drier countries but not represented in our historical data. For this reason, our projections for the warmest, driest areas of the country (e.g. the South East of England) are subject to the highest degree of uncertainty. Since this uncertainty inflates with the extent of climate change, the results for the most extreme scenarios (e.g. the high emission scenario for 2060) for these areas should be interpreted very cautiously. Conversely, the results for the North of England, Wales, Scotland and Northern Ireland, for which climate change lies within the range of our historic data, should be more robust.

Considering our measure of financial impacts, FGM, two important limitations need to be acknowledged. First, since FGM is defined as the difference between revenues and variable costs, all farm fixed costs (e.g. machineries, buildings, rent, etc.) are not included in the analysis. Secondly, conversion costs are also 
excluded. In other words, all changes in land use and FGM refer to equilibrium conditions and do not take into account possible costs encountered in order to reach these new equilibriums.

Finally, our analysis focuses on the impact of changes in temperature and precipitation, and does not include other things that might be affected by climate change. For example, Mendelsohn and Dinar (2009) and others suggest that increased $\mathrm{CO}_{2}$ fertilization may improve crop yields. However, there may be a trade-off between quantity and quality, as the projected increase in crop growth could be offset by a decline in nutritional value (Jablonski, Wang, and Curtis, 2002). Another factor which is likely to change in the future is pollination. Current research (e.g. Potts et al., 2010) points to a significant decline in pollinator populations in recent years. Other commentators point to the risks of climate change permitting the transmigration of new crop pests and diseases (Chakraborty et al., 2000). A major difficulty facing the incorporation of these and further effects is the incomplete science base available for such analyses. Given this, we believe that the decision to control out such complexities yields an analysis which is a useful starting point for considering the impacts of this most challenging problem on this most vital of ecosystem services.

\section{References}

Abson et al., 2012

Adams R. M., (1989) Global climate change and agriculture: an economic perspective, American Journal of Agricultural Economics, vol. 71, pp. 1272-1279.

Amemiya T. (1973) Regression analysis when the dependent variable is truncated normal, Econometrica, vol. 41, pp. 997-1016.

Austin R.B., Arnold M.H. (1989) Variability in wheat yields in England: analysis and future prospects, in J.R. Anderson and P.B.R. Hazell (Eds.) Variability in grain yields: implications for agricultural research and policy in developing countries, Johns Hopkins University Press, Baltimore.

Bateman et al., 2012

Bateman I.J., Mace G.M., Fezzi C., Atkinson G., Turner K. (2011) Economic analysis for ecosystem service assessment, Environmental and Resource Economics, vol. 48, pp. 177-218.

Brady M., Irwin E. (2011) Accounting for spatial effects in economics models of land use: recent developments and challenges ahead, Environmental and Resource Economics, vol. 48, pp. 487-509.

Chakraborty S., Tiedemann A.V., Teng P.S. (2000) Climate change: potential impact on plant disease, Environmental Pollution, vol. 108, pp.317-326. 
Chambers R.G., Just R.E. (1989) Estimating multioutput technologies, American Journal of Agricultural Economics, vol. 71, pp. 980-995.

Defra (2000) Climate Change \& Agriculture in the United Kingdom, Defra, London.

Fezzi, C. and Bateman, I.J. (2011) Structural agricultural land use modeling for spatial agro-environmental policy analysis, American Journal of Agricultural Economics, vol. 93, pp. 1168-1188.

Fezzi C., Bateman I.J., Schlenker W. (2011) Aggregation bias and non-linear effects in Ricardian models of climate change, CSERGE Working Paper, to be submitted.

Fezzi C., Rigby D., Bateman I.J., Hadley D., Posen P. (2008) Estimating the range of economic impacts on farms of nutrient leaching reduction policies, Agricultural Economics, vol. 29, pp. 197-205.

Fezzi C., Hutchins M., Rigby D., Bateman I.J., Posen P., Hadley, D. (2010) Integrated assessment of Water Framework Directive nitrate reduction measures, Agricultural Economics, vol. 41, pp. 123-134.

Intergovernmental Panel on Climate Change (2007) Climate change 2007: synthesis report, (Eds: A. Allali, R. Bojariu, S. Diaz, I. Elgizouli, D. Griggs, D. Hawkins, O. Hohmeyer, B.P. Jallow, L. Kajfez-Bogataj, N. Leary, H. Lee, D. Wratt), published by the Intergovernmental Panel on Climate Change, Geneva.

Jablonski L. M., Xianzhong W., Curtis P.S. (2002) Plant reproduction under Elevated CO2 Conditions: A Meta-Analysis of Reports on 79 Crop and Wild Species, New Phytologist, vol. 156, pp. 9-26.

Just R.E. (2000) Some guiding principles for empirical production research in agriculture, Agricultural and Resource Economics Review, vol. 29, pp. 138-158.

Langpap, C., I. Hascic, and J. Wu (2008) Protecting watershed ecosystems through targeted local land use policies, American Journal of Agricultural Economics, vol. 90, pp. 684-700.

Lichtenberg E. (1989) Land quality, irrigation development, and cropping patterns in the Northern High Plains, American Journal of Agricultural Economics, vol. 71, pp. 187-194.

Lobell D.B, Schlenker W., Costa-Roberts J. (2011) Climate trends and global crop production since 1980, Science, pp. 616-620.

Mendelsohn R., Dinar A. (2009) Climate change and agriculture: an economic analysis of global impacts, adaptation and distributional effects, Edward Edgar, Cheltenham (UK).

Millennium Ecosystem Assessment (MA) (2005) Ecosystems and Human Well-being: A Framework for Assessment, Island Press, Washington DC, 2005.

National Statistics (2010) Agriculture in the United Kingdom 2009, Department for Environment, Food and Rural Affairs; Department of Agriculture and Rural Development (Northern Ireland); Welsh Assembly Government; The Department for Rural Affairs and Heritage; The Scottish Government; and the Rural and Environment Research and Analysis Directorate.

Nix, J. S. (2009) Farm Management Pocketbook 2010, The Anderson Centre

Nix, J. S. (2006) Farm Management Pocketbook 2007, The Anderson Centre 
Nordhaus W.D., Yang Z. (1996) A regional dynamic general-equilibrium model of alternative climate change strategies, American Economic Review, vol. 86, pp. 741-765.

Nakicenovic N., Swart R. (2000) Special Report on Emissions Scenarios, Cambridge University Press, Cambridge.

Office for National Statistics (2010) Annual Abstract of Statistics, No 146, Palgrave Macmillan, London.

Plantinga A.J. (1996) The effect of agricultural policies on land use and environmental quality, American Journal of Agricultural Economics, vol. 78, pp. 1082-1091.

Potts S.G., Biesmeijer J.C., Kremen C., Neumann P., Schweiger O., Kunin W.E. (2010) Global pollinator declines: trends, impacts and drivers, Trends in Ecology and Evolution, vol. 25, pp. 345-353.

Pudney S. (1989) Modelling individual choice: the econometrics of corners, kinks and holes, Blackwell Publishers, Cambridge.

Sen et al., 2012)

Schlenker W., Hanemann M.W., Fisher A.C. (2006) The impact of global warming on U.S. agriculture: an econometric analysis of optimal growing conditions, Review of Economics and Statistics, vol. 88, pp. 113-125.

Yen S.T., Lin B.H., Smallwood D.M. (2003) Quasi- and simulated-likelihood approaches to censored demand systems: food consumption by food stamp recipients in the United States, American Journal of Agricultural Economics, vol. 85, pp. 458-478.

Tobin J. (1958) Estimation for relationships with limited dependent variables, Econometrica, vol. 26, pp. 24-36.

Van Liedekerke M., Jones A., Panagos P. (2006) ESDBv2 Raster Library - a set of rasters derived from the European Soil Database distribution v2.0, published by the European Commission and the European Soil Bureau Network, CD-ROM, EUR 19945 EN.

UK Climate Impacts Programme (UKCIP) (2009) UK climate projection: briefing report, Met Office Hadley Centre, Exeter, UK.

Williams, R.L. (2000) A note on robust variance estimation for cluster-correlated data, Biometrics, vol. 56, pp. 645-646.

Wu J.R., Adams M., Kling C.L., Tanaka K. (2004) From microlevel decisions to landscape changes: an assessment of agricultural conservation policies, American Journal of Agricultural Economics, vol. 81, pp. 26-41.

Zellner A., Lee T.H. (1965) Joint estimation of relationships involving discrete random variables, Econometrica, vol. 33, pp. 382-394. 


\section{Appendix I: The impact of variation in prices on projections of climate change impacts}

Figure 4 holds real prices constant at 2004 levels for its analysis of the impacts of climate change across three periods. However, agriculture is characterised by price instability and this has been particularly evident during the past decade. To illustrate the substantial impacts of price instability in Figure A1 we consider a single climate change period (2004 to 2040) and take prices from three recent years; 2004 (Fezzi et al. 2010), 2006 (Nix, 2006) and 2009 (Nix, 2009). Allowance is made for intervening inflation from 2004 to the latter two years, bringing all three to 2004 real value equivalents. These are then applied to the changes in land use and livestock intensities projected for 2004 to 2040 under the low emission scenario.

Analysis of the spatial patterns illustrated in Figure A1 reveals that these are similar to those of Figure 5 with the south and eastern lowlands of England faring worst from climate change while other more upland areas benefit from such change. Further comparison of these figures shows that even the absolute shifts in FGM induced by price changes are of a similar magnitude to those arising from climate change. This suggests that price volatility might be at least as important to the financial prosperity of UK agriculture (if not more given that the above analysis only considered price variation over a relatively short period). Note that this comparison does not take into account possible land use changes arising from changes in prices. However, these are likely to be minor if farmers' expectations of future prices do not differ substantially from present prices.

Figure A1: The impact of climate change (low emissions scenario) on FGM between 2004 and 2040 evaluated using three recent sets of real prices
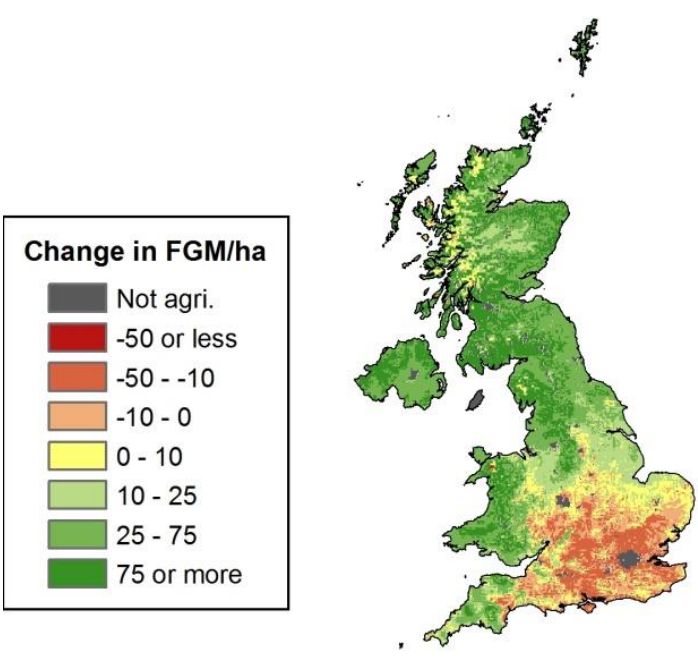

Predicted change in FGM 2040 (using 2004 prices)

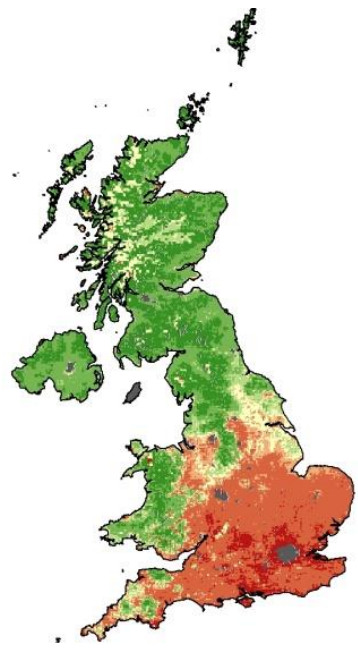

Predicted change in FGM 2040 (using 2006 prices)

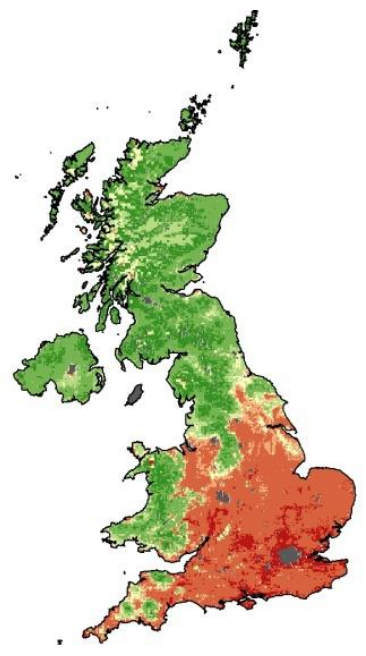

Predicted change in FGM 2040 (using 2009 prices) 
Tables

Table 1: Descriptive statistics

\begin{tabular}{|c|c|c|c|c|c|c|c|c|c|c|c|c|}
\hline \multirow[b]{2}{*}{ Land-Use } & \multicolumn{8}{|c|}{ Area Means } & \multicolumn{4}{|c|}{ UK Total } \\
\hline & $N W$ & $N E$ & $E W M$ & $E A$ & $L S E$ & $S W$ & $S C T$ & $W A$ & Mean & $S d$ & $\operatorname{Max}$ & Min \\
\hline Cereals & 107.4 & 30.5 & 116.8 & 172 & 108.4 & 71.6 & 30.7 & 12.4 & 68.1 & 64.5 & 347.5 & 0 \\
\hline Oilseed Rape & 9.8 & 0.8 & 11.0 & 12.8 & 11.4 & 4.5 & 2.3 & 0.3 & 5.6 & 11.2 & 124.7 & 0 \\
\hline Root Crops & 10.3 & 3.6 & 16.1 & 32.3 & 2.2 & 2.0 & 2.1 & 0.7 & 7.0 & 16.2 & 167.4 & 0 \\
\hline T. Grassland & 23.7 & 39.0 & 33.0 & 10.7 & 32.4 & 53.1 & 29.9 & 31.0 & 31.1 & 35.7 & 268.2 & 0 \\
\hline P. Grassland & 93.6 & 173.3 & 116.4 & 35.9 & 93.1 & 168.9 & 50.3 & 193.5 & 95.2 & 94.9 & 395.3 & 0 \\
\hline Rough Graz. & 78.7 & 86.4 & 10.2 & 5.9 & 9.7 & 20.2 & 252.2 & 92.2 & 121.9 & 161.0 & 400.0 & 0 \\
\hline Other Land & 30.1 & 16.2 & 41.5 & 65.2 & 56.5 & 34.4 & 0.0 & 17.0 & 23.2 & 31.6 & 289.5 & 0 \\
\hline Total Ag Land & 353.6 & 349.9 & 344.9 & 334.7 & 313.7 & 354.8 & 367.5 & 347.1 & 352.6 & 67.0 & 400.0 & 0 \\
\hline Dairy & 42.5 & 161.3 & 84.9 & 20.7 & 54.9 & 145.5 & 19.4 & 82.1 & 57.6 & 91.8 & 1129 & 0 \\
\hline Beef & 143.0 & 208.9 & 165.9 & 56.3 & 110.7 & 218.2 & 87.6 & 194.8 & 130.2 & 125.5 & 1221 & 0 \\
\hline Sheep & 743.7 & 935.4 & 596.3 & 79.3 & 346.4 & 582.7 & 420.4 & 1865.9 & 608.6 & 766.4 & 11290 & 0 \\
\hline
\end{tabular}

Notes: Areas (ha) and livestock numbers (head) per 2km grid square (400ha). Regions: North West (NW), Yorkshire and North East (YNE), East and West Midlands (EWM), East Anglia (EA), London and South East (LSE), South West (SW), Wales (WA) and Scotland (SCT) 
Table 2: Selected land use share equations estimates

\begin{tabular}{lll}
\hline Variable & Oilseed rape & Temp. grassland \\
\hline mean altitude & $0.043 *$ & -0.653 \\
mean altitude squared & $-0.000 * *$ & $-0.001 * * *$ \\
mean temperature & $11.603 * * *$ & $-24.213 * * *$ \\
mean temperature squared & $-0.442 * * *$ & $0.701 * *$ \\
accumulated rainfall & -0.022 & $-0.918 *$ \\
accumulated rainfall squared & $0.000 * * * *$ & $0.000 * *$ \\
depth to rock & -0.000 & $0.305 *$ \\
depth to rock squared & -0.000 & -0.000 \\
volume of stones & $-55.603 * * *$ & -32.856 \\
volume of stones squared & $275.705 * *$ & $301.686 *$ \\
share of agricultural land with slope $>6$ degrees & $-0.010 *$ & $0.303 * *$ \\
dominant soil = fine & $1.337 * * *$ & $-1.806 * * *$ \\
dominant soil = medium fine & 0.191 & -0.194 \\
dominant soil = coarse & $-0.729 * *$ & -0.366 \\
dominant soil = peat & $-3.258 * * *$ & $-0.366 * * *$ \\
share of urban area & $-0.016 *$ & -0.172 \\
share of nitrate sensitive area & $0.017 * *$ & -0.109 \\
share of national park & $-0.021 * *$ & $-0.029 * *$ \\
share of environmentally sensitive area & $-0.020 * *$ & -0.012
\end{tabular}

Notes: Yearly fixed effects and heteroskedastic error component parameters included in the model but not reported in the table to preserve space. Standard errors corrected for cell-specific autocorrelation as in Williams (2000). Significance: “*” $=\mathrm{t}$-stat $>2, “ * * "=\mathrm{t}$-stat $>3$, “****" $=\mathrm{t}$-stat $>4, “ * * * * "=\mathrm{t}$-stat $>10$. 
Table 3: Forecasting performance

\begin{tabular}{lccc}
\hline Variable & MAE Structural & MAE Logit & $\hat{s}(x)$ \\
\hline Cereals (ha) & 28.77 & 36.98 & 70.96 \\
Oilseed rape (ha) & 8.61 & 11.56 & 17.54 \\
Root crops (ha) & 7.21 & 6.91 & 17.14 \\
Temporary grassland (ha) & 13.07 & 15.86 & 22.33 \\
Permanent grassland (ha) & 50.44 & 57.99 & 99.03 \\
Rough grazing (ha) & 28.53 & 29.48 & 97.92 \\
Dairy (head) & & & \\
Beef (head) & 48.29 & -- & 92.69 \\
Sheep (head) & 67.51 & -- & 120.11 \\
\hline
\end{tabular}

Notes: Forecasting performance tested on England and Wales data in year 2004 (37980 observations).

Only $5 \%$ of these observations are used in estimation so this is mainly an out-of-sample forecasting test. $\mathrm{MAE}=$ mean absolute error, $\hat{s}(x)=$ standard error of the variable. 
Table 4: Descriptive statistics of the climatic variables (baseline and scenarios)

\begin{tabular}{|c|c|c|c|c|c|}
\hline Year & Scenario & Variable & Mean & Minimum & Maximum \\
\hline \multirow[t]{2}{*}{2004} & \multirow[t]{2}{*}{ Baseline } & Temp $\left({ }^{\circ} C\right)$ & 11.7 & 4.7 & 14.9 \\
\hline & & $\operatorname{Prec}(m m)$ & 450.8 & 206.7 & 1699.9 \\
\hline \multirow[t]{4}{*}{2020} & \multirow[t]{2}{*}{ Low emissions } & Temp $\left({ }^{\circ} C\right)$ & 12.9 & 5.9 & 16.2 \\
\hline & & $\operatorname{Prec}(m m)$ & 446.9 & 201.9 & 1654.8 \\
\hline & \multirow[t]{2}{*}{ High emissions } & Temp $\left({ }^{\circ} C\right)$ & 13.0 & 6.0 & 16.3 \\
\hline & & $\operatorname{Prec}(m m)$ & 443.7 & 198.0 & 1654.5 \\
\hline \multirow[t]{4}{*}{2040} & \multirow[t]{2}{*}{ Low emissions } & Temp $\left({ }^{\circ} C\right)$ & 13.4 & 6.4 & 16.9 \\
\hline & & $\operatorname{Prec}(m m)$ & 432.4 & 192.6 & 1598.9 \\
\hline & \multirow[t]{2}{*}{ High emissions } & Temp $\left({ }^{\circ} C\right)$ & 13.6 & 6.5 & 17.1 \\
\hline & & Prec $(m m)$ & 429.1 & 190.3 & 1591.2 \\
\hline \multirow[t]{4}{*}{2060} & \multirow[t]{2}{*}{ Low emissions } & Temp $\left({ }^{\circ} C\right)$ & 13.8 & 6.7 & 17.2 \\
\hline & & $\operatorname{Prec}(m m)$ & 420.0 & 184.0 & 1542.5 \\
\hline & \multirow[t]{2}{*}{ High emissions } & Temp $\left({ }^{\circ} C\right)$ & 14.2 & 7.4 & 18.1 \\
\hline & & $\operatorname{Prec}(\mathrm{mm})$ & 404.8 & 171.2 & 1522.9 \\
\hline
\end{tabular}

Notes: Temp = average temperature in the crop growing season, Prec $=$ total precipitation in the growing season. Statistics refer to the entire UK. The low/high emissions scenarios correspond to the SRES B1/SRES A1F1 scenario in the IPCC Special Report on Emissions Scenarios (Nakicenovic and Swart, 2000). 
Table 5: Average projected land uses hectares and livestock numbers

\begin{tabular}{|c|c|c|c|c|c|c|c|c|c|c|c|}
\hline Year & Scenario & $\begin{array}{l}\text { Permanent } \\
\text { grassland } \\
(h a)\end{array}$ & $\begin{array}{l}\text { Temporary } \\
\text { grassland } \\
(h a)\end{array}$ & $\begin{array}{c}\text { Rough } \\
\text { grazing } \\
(h a)\end{array}$ & $\begin{array}{l}\text { Cereals } \\
(h a)\end{array}$ & $\begin{array}{l}\text { Oilseed } \\
\text { Rape } \\
(h a)\end{array}$ & $\begin{array}{c}\text { Roots } \\
(h a)\end{array}$ & $\begin{array}{c}\text { Other } \\
\text { farmland } \\
(h a)\end{array}$ & $\begin{array}{l}\text { Dairy } \\
\text { (head) }\end{array}$ & $\begin{array}{l}\text { Beef } \\
\text { (head) }\end{array}$ & $\begin{array}{l}\text { Sheep } \\
\text { (head) }\end{array}$ \\
\hline 2004 & Baseline & 85.1 & 19.4 & 98.2 & 61.0 & 7.4 & 0.6 & 53.4 & 28.6 & 90.7 & 535.8 \\
\hline \multirow[t]{2}{*}{2020} & $\begin{array}{l}\text { Low } \\
\text { emissions }\end{array}$ & 110.6 & 21.0 & 74.2 & 47.8 & 4.4 & 0.9 & 65.2 & 49.3 & 84.2 & 524.4 \\
\hline & $\begin{array}{l}\text { High } \\
\text { emissions }\end{array}$ & 110.7 & 20.9 & 74.9 & 48.5 & 4.5 & 0.9 & 63.8 & 48.8 & 86.1 & 530.0 \\
\hline \multirow[t]{2}{*}{2040} & $\begin{array}{l}\text { Low } \\
\text { emissions }\end{array}$ & 113.5 & 22.2 & 71.0 & 41.1 & 3.3 & 1.1 & 71.9 & 55.2 & 75.6 & 498.3 \\
\hline & $\begin{array}{l}\text { High } \\
\text { emissions }\end{array}$ & 113.6 & 22.8 & 72.3 & 37.7 & 2.9 & 1.0 & 73.7 & 57.2 & 72.3 & 488.4 \\
\hline \multirow[t]{2}{*}{2060} & $\begin{array}{l}\text { Low } \\
\text { emissions }\end{array}$ & 110.3 & 22.7 & 72.6 & 36.7 & 2.8 & 1.2 & 77.7 & 57.2 & 67.2 & 473.8 \\
\hline & $\begin{array}{l}\text { High } \\
\text { emissions }\end{array}$ & 107.0 & 26.0 & 84.3 & 21.7 & 1.2 & 1.4 & 82.5 & 65.7 & 55.6 & 431.8 \\
\hline
\end{tabular}

Notes: Average hectares (ha) and livestock heads (head) for agricultural $2 \mathrm{~km}$ grid square within the UK. The low/high emissions scenarios correspond to the SRES B1/SRES A1F1 scenario in the IPCC Special Report on Emissions Scenarios (Nakicenovic and Swart, 2000). 
Figures

Figure 1: Cereals and rough grazing in 2004: model predictions (LHS) and JAC data (RHS)

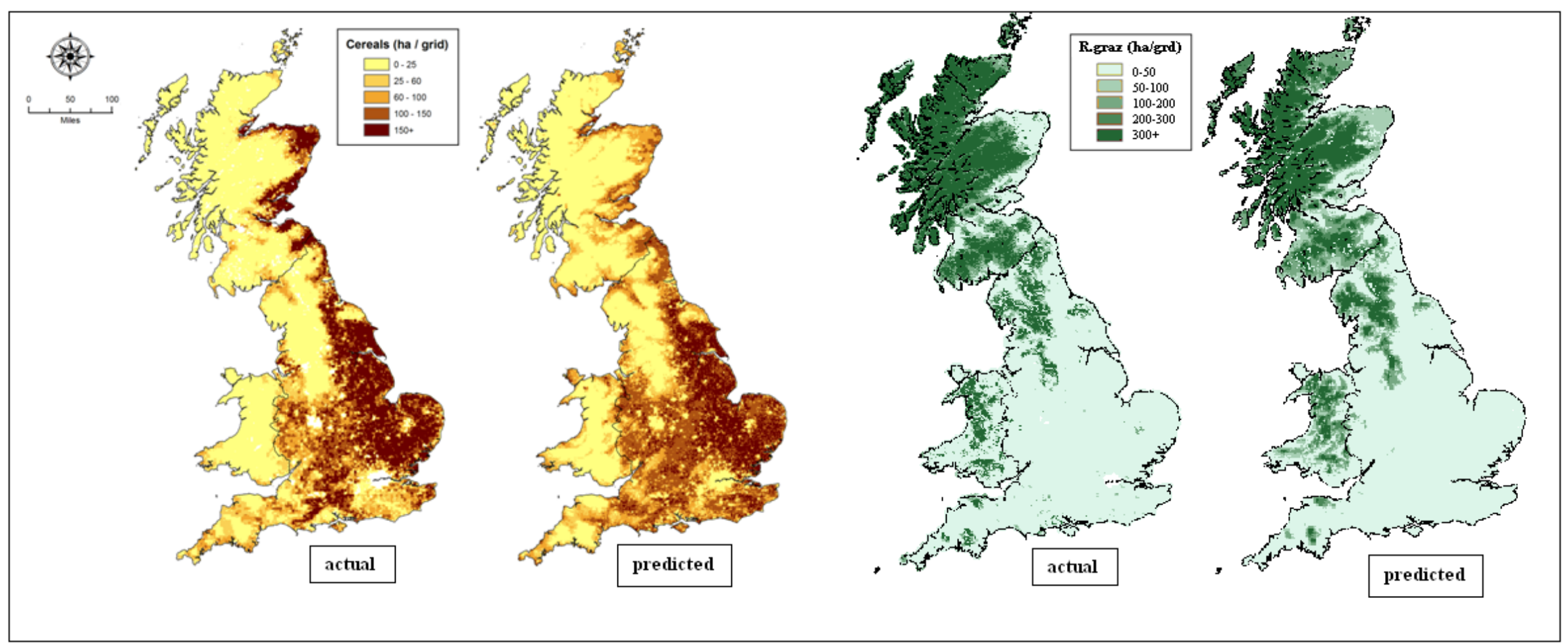


Figure 2: Mean temperature (left hand pair) and precipitation (right hand pair) in the growing season in 2004 and 2040 under the UKCIP high emissions scenario.

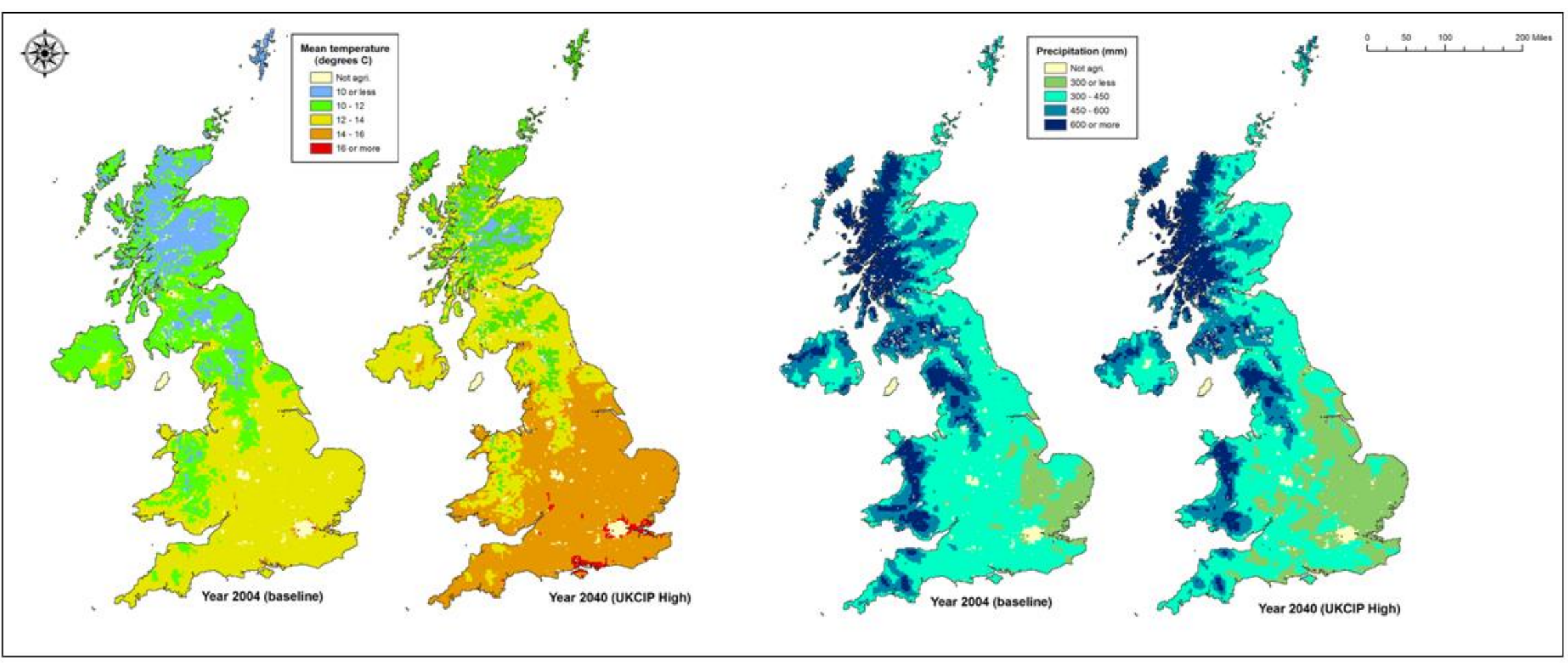


Figure 3: Change in land use (cereals and temporary grassland) and livestock numbers (dairy cattle) under the UKCIP low emission scenario for 2020, 2040, 2060

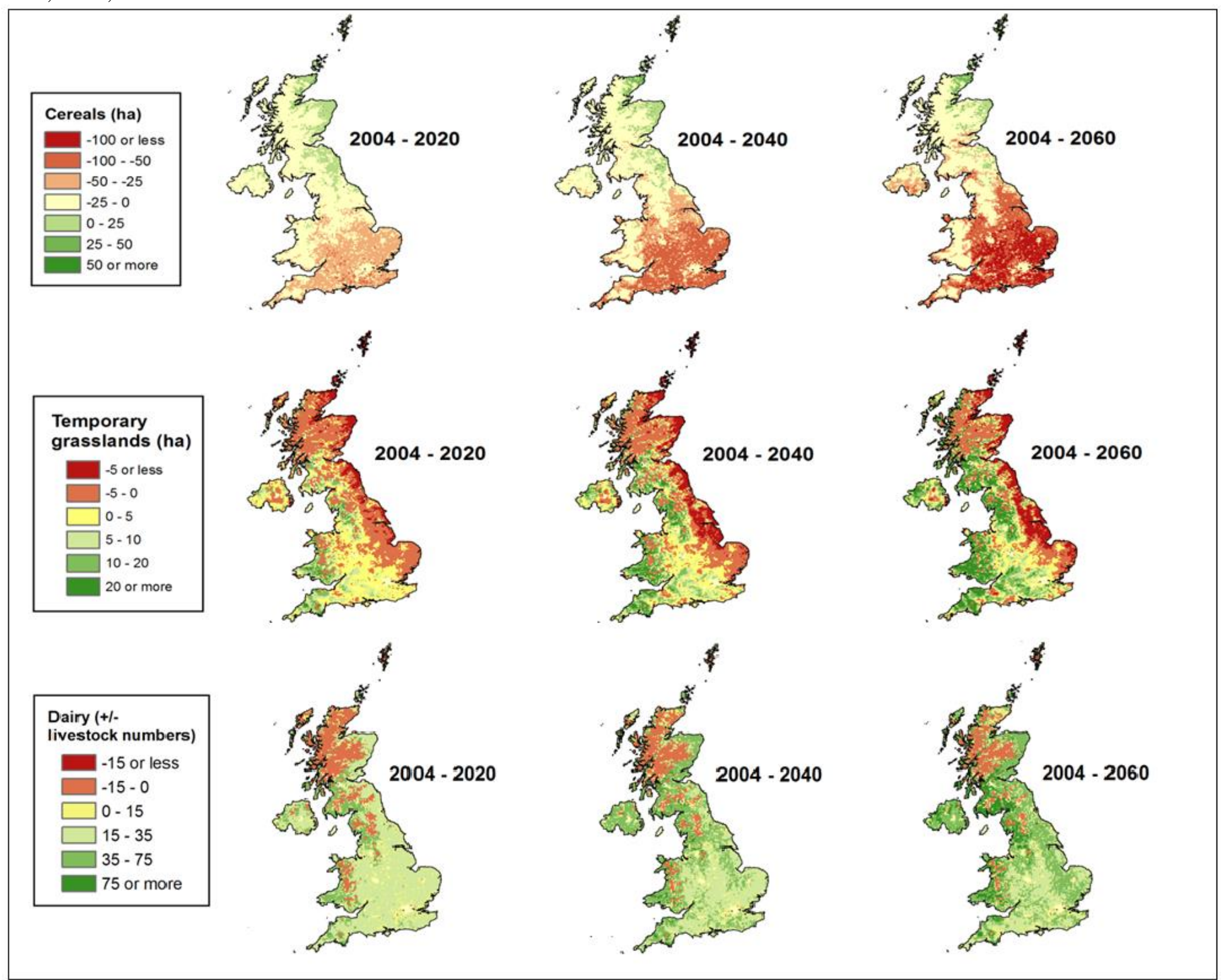

Notes: Both hectares and livestock numbers refers to changes within a $2 \mathrm{~km}$ grid square (400 ha). 
Figure 4: Impact of climate change (UKCIP low emission scenario, 2020, 2040, 2060) on farm gross margin (£/ha) in 2020 compared to its level in 2004.

\begin{tabular}{|l}
\hline Change in FGM/ha \\
Not agri. \\
-50 or less \\
$-50--10$ \\
$-10-0$ \\
$0-10$ \\
$10-25$ \\
$25-75$ \\
75 or more \\
\hline
\end{tabular}
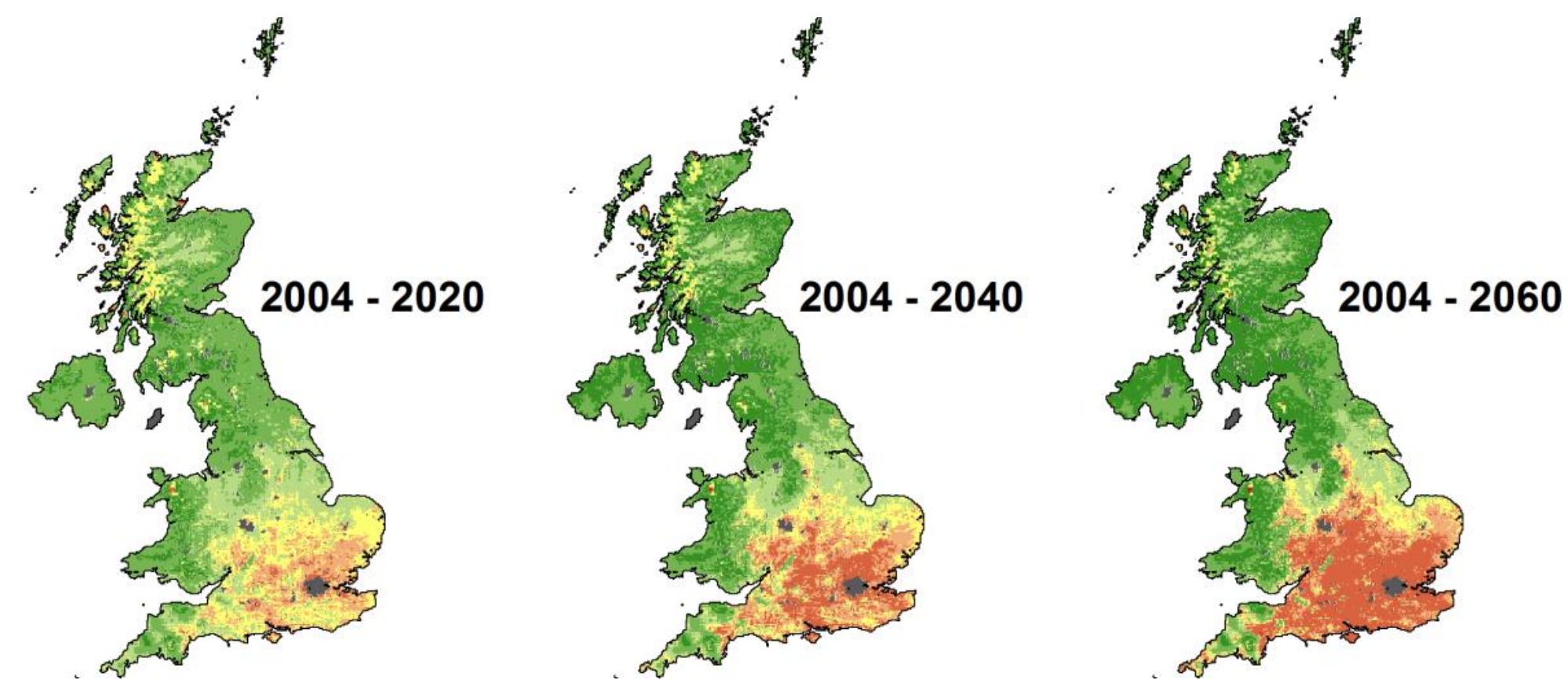